\title{
BATF regulates the development and function of IL-17 producing iNKT cells
}

\author{
Kimberly L Jordan-Williams ${ }^{1}$, Stacie Poston ${ }^{1}$ and Elizabeth J Taparowsky ${ }^{2 *}$
}

\begin{abstract}
Background: BATF plays important roles in the function of the immune system. Batf null mice are deficient in both CD4 ${ }^{+}$Th17 cells and T follicular helper cells and possess an intrinsic B cell defect that leads to the complete absence of class switched Ig. In this study, Tg mice overexpressing BATF in T cells were used together with Batf null mice to investigate how altering levels of BATF expression in T cells impacts the development and function of a recently characterized population of iNKT cells expressing IL-17 (iNKT-17).

Results: BATF has a direct impact on IL-17 expression by iNKT cells. However, in contrast to the Th17 lineage where BATF activates IL-17 expression and leads to the expansion of the lineage, BATF overexpression restricts overall iNKT cell numbers while skewing the compartment in vivo and in vitro toward an iNKT-17 phenotype.

Conclusions: This work is the first to demonstrate that BATF joins RORyt as the molecular signature for all IL-17 producing cells in vivo and identifies BATF as a component of the nuclear protein network that could be targeted to regulate IL-17-mediated disease. Interestingly, these studies also reveal that while the $1 / 17 a$ gene is a common target for BATF regulation in Th17 and iNKT-17 cells, this regulation is accompanied by opposite effects on the growth and expansion of these two cell lineages.
\end{abstract}

Keywords: BATF, Activator-protein-1, iNKT cells, IL-17, Mouse models

\section{Background}

BATF is a basic leucine zipper transcription factor that dimerizes with the JUN proteins to direct patterns of activator protein-1 (AP-1)-mediated gene expression in the immune system [1]. The impact of disrupting BATF function in vivo has been examined by several groups [2-5]. Mice in which BATF is overexpressed using a T cell-specific promoter display a reduced number of iNKT cells [6], an increased number of $\mathrm{CD}_{4}^{+} \mathrm{T}$ cells expressing IL-17 (Th17) [5] and an altered cytokine environment that promotes the gross overproduction of class switched Ig by B cells [7]. Batf null mice are viable, yet display a severe deficiency in Th17 and $\mathrm{T}$ follicular helper cells $[2,3,5]$. The $\mathrm{T}$ cell deficiencies are combined with an intrinsic B cell defect blocking the production of class switched Ig to impair the immune response of these animals to antigen challenge [2,3]. The dramatic consequences of altering BATF expression in vivo

\footnotetext{
* Correspondence: taparows@purdue.edu

2Department of Biological Sciences, Hansen Life Sciences Research Building, Room 219, 201 South University Street, West Lafayette, IN, USA

Full list of author information is available at the end of the article
}

provides evidence that BATF functions to coordinate immune system activities critical in autoimmunity, inflammation and the host response to pathogens.

The ability of BATF to promote the differentiation of naïve $\mathrm{CD} 4^{+} \mathrm{T}$ cells to the Th17 lineage has been shown to rely on the formation of IRF4/BATF protein complexes that bind and transactivate a number of genes, including Il17a/f [8]. Interestingly, we have observed a negative influence of BATF on the development of iNKT cells $[6,9]$ and therefore sought to examine how these two opposing activities of BATF may influence the development of a recently identified subset of iNKT cells that expresses IL-17 [10-13]. Murine iNKT-17 cells are a CD4 NK1.1 population that is enriched in peripheral LN (PLN) and respond following stimulation by rapidly secreting IL-17. iNKT-17 cells express RORyt and additional markers that define them as a lineage distinct from classic iNKT cells. A role for iNKT-17 cells has been demonstrated in experimental models of airway disease, asthma and collagen-induced arthritis [12,14,15]. iNKT-17 cells are over-represented in NOD mice where their influence in the pancreas exacerbates the development of diabetes [16]. In the present

\section{Biomed Central}

(c) 2013 Jordan-Williams et al.; licensee BioMed Central Ltd. This is an Open Access article distributed under the terms of the Creative Commons Attribution License (http://creativecommons.org/licenses/by/2.0), which permits unrestricted use, distribution, and reproduction in any medium, provided the original work is properly cited. 
study, using mouse models of BATF overexpression (CD2$H A-B A T F)$ and deficiency $\left(B a t f^{j Z / \Delta Z}\right.$ ), we demonstrate the importance of BATF to the development of iNKT-17 cells. Despite the overall reduction in the number of iNKT cells in CD2-HA-BATF mice, the majority express IL-17. Likewise, while peripheral iNKT cell numbers are increased in Batf $^{\Delta Z / \Delta Z}$ mice, the cells are deficient in IL-17 production. These data are consistent with results in Th17 cells $[5,17]$ and suggest that BATF-containing protein complexes transactivate the Il17a/f gene in NKT cells as well. The novel finding is that the function of BATF as an IL-17 inducer is separate from its effect on cell growth since Th17 cell numbers are expanded in the presence of BATF, while iNKT cell numbers are reduced. To identify an in vitro system that would facilitate the study of BATF-mediated gene regulatory events relevant to the iNKT cell lineage, we describe features of the DN32.D3 hybridoma [9] that indicate similarity to the iNKT-17 lineage, including the BATF-dependent expression of $I l 17 a$ mRNA. We conclude that BATF joins RORyt as the molecular signature for all IL-17 producing cells in vivo and represents an essential component of a nuclear protein network that could be targeted to regulate IL-17-mediated disease.

\section{Results and discussion}

\section{BATF controls $\mathrm{CD}^{+}{ }^{+}$Th17 cell differentiation}

To test if CD2-HA-BATF Tg mice display the increase in IL-17 expression reported for a separate model of BATF overexpression in vivo [5], splenocytes were stimulated with anti-CD3 and anti-CD28 antibodies and RNA isolated after $48 \mathrm{~h}$. For comparison, cells from non-Tg (WT) and $B a t f^{Z / \Delta Z}$ mice were used. Gene expression analysis by quantitative (q)RT-PCR revealed the expected high level of $I l 17 a$ mRNA in Tg cells and undetectable levels of Ill7a mRNA in Batf ${ }^{A / \Delta Z}$ cells (Figure 1A). To implicate altered Th17 development as the major contributor to this change in $I l 17 a$ expression, naïve $\mathrm{CD} 4^{+}$splenocytes from $\mathrm{Tg}$, WT and Batf $f^{\Delta Z / \Delta Z}$ mice were subjected to in vitro protocols skewing differentiation toward the Th17 lineage or toward Th1 cells as a control. Differentiation was assessed by measuring the expression of genes specific for these $\mathrm{CD}^{+} \mathrm{T}$ cell subsets. As shown in Figure 1B, levels of Th1 associated transcripts (Tbet and Ifny) were statistically similar across all samples, while levels of Th17 associated transcripts (Roryt, Il17a, Il23R and Il21) were elevated in Tg samples and essentially undetectable in $B a t f^{A Z / \Delta Z}$ samples (Figure 1C). These findings in CD2-HA-BATF mice confirm a positive role for BATF in the differentiation of Th17 cells.

\section{Levels of BATF correlate with altered iNKT cell numbers} in vivo

Mice overexpressing BATF in thymic T cells $\left(p 56^{l c k} H A-\right.$ $B A T F)$ display a reduced number of iNKT cells [6].
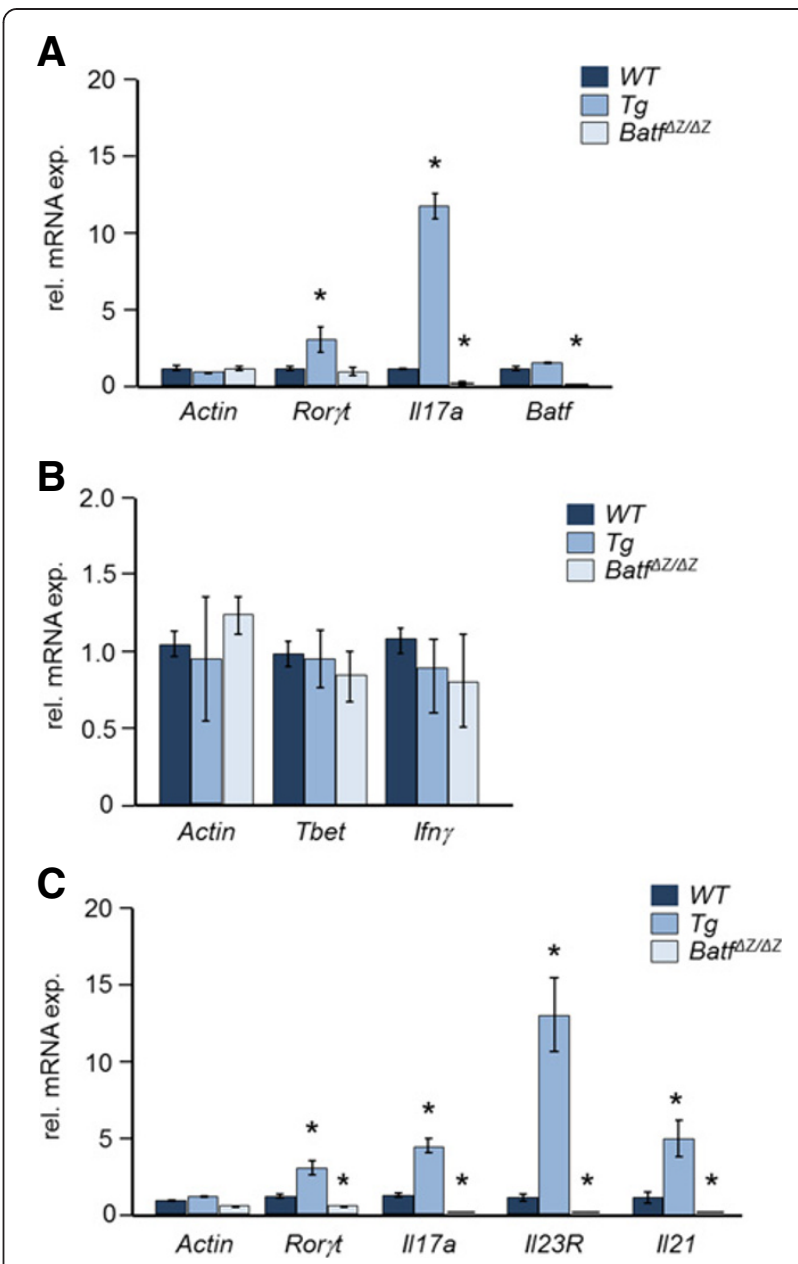

Figure 1 BATF impacts Th17 differentiation in vivo and in vitro. A RNA prepared from stimulated, $\mathrm{CD}^{+} \mathrm{T}$ cells of the indicated genotypes was analyzed for Th17-associated transcripts by qRT-PCR. B and $\mathbf{C}$ Naiive $\mathrm{CD}^{+}{ }^{+} \mathrm{T}$ cells of the indicated genotypes were cultured in vitro under conditions skewing differentiation to Th1 (B) or Th17 (C) cells. After 5 days, RNA was analyzed for the indicated transcripts by qRT-PCR. Data were averaged from $6(n=6)(\mathbf{A})$ or $3(n=3)(\mathbf{B}$ and $\mathbf{C})$ mice per genotype. Bars indicate standard error. ${ }^{*} \mathrm{p}$ values $<0.05$.

Interestingly, quantification of thymic iNKT cells in Batf $\triangle Z / \Delta Z$ mice revealed a number equivalent to WT mice [2]. As the CD2-HA-BATF transgene directs BATF overexpression to all $\mathrm{T}$ cells (thymic and peripheral) [7], iNKT cells were re-examined and compared to numbers in WT and Batf $\overline{Z Z / \Delta Z}$ mice. The percentage of $T$ cells positive for interaction with glycolipid-loaded CD1d tetramers was assessed by flow cytometry using single cell suspensions from thymus, spleen and PLN. Whether calculated on the basis of percentage (Figure 2A) or absolute number (Figure 2B), the results confirm that iNKT cells are under-represented in the thymus of $\mathrm{Tg}$ mice and extend that observation by showing fewer iNKT cells in the spleen and PLN as well. These data confirm that BATF deficiency does not impact the iNKT cell 


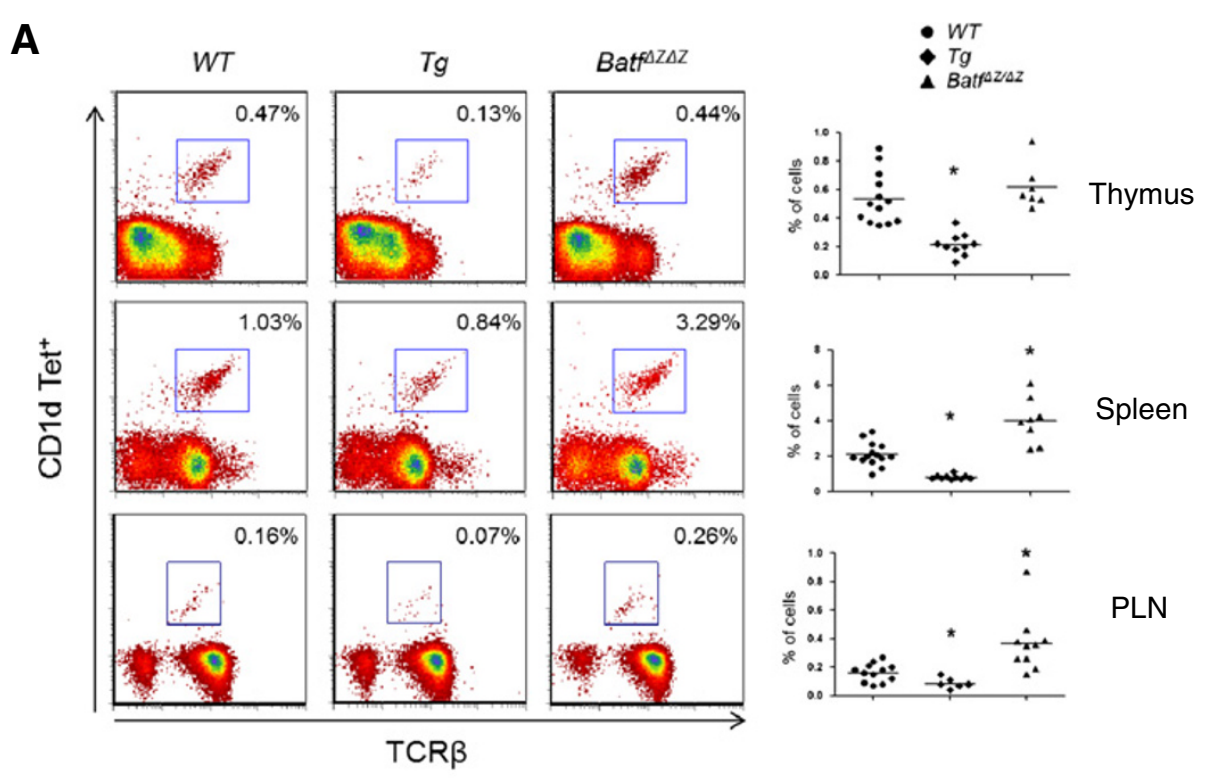

B

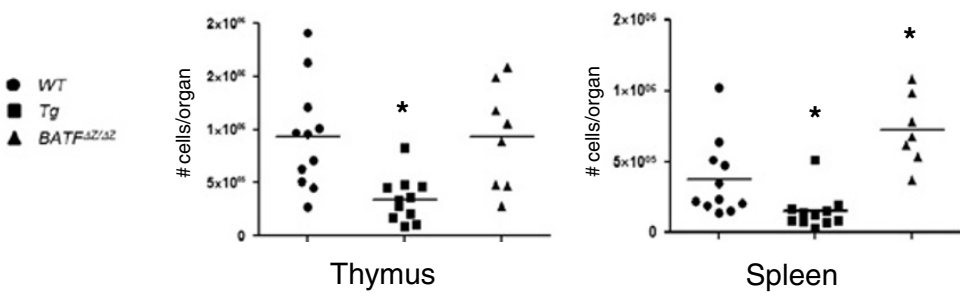

Figure 2 BATF alters iNKT cells numbers in vivo. A iNKT cells in single cell suspensions prepared from thymus, spleen and PLN of the indicated genotypes were detected by flow cytometry using glycolipid-loaded mouse CD1d tetramers. Cells gated are B220 and iNKT cells are identified as TCR ${ }^{+}$Tet $^{+}$(box). Representative flow plots are shown with \% iNKT cells indicated. The mean and distribution of data obtained from at least 6 mice per genotype are presented on the right $(n \geq 6)$. ${ }^{*} p$ values $<0.05$. B Analysis of iNKT cells was performed as described in $\mathbf{A}$ and data expressed as total number of cells per indicated organ. The analysis of PLN was not performed. The mean and distribution of data obtained from the organs of at least 7 mice per genotype $(n \geq 7)$ are presented. ${ }^{*} p$ values $<0.05$.

population in the thymus, yet do reveal, for the first time, that $B a t f^{\mu Z / \Delta Z}$ mice possess a statistically significant increase in the number of peripheral iNKT cells.

In previous studies, we reported that the residual iNKT cells in $p 56^{\text {lck } H A-B A T F}$ mice were disproportionately $\mathrm{CD} 44^{+} \mathrm{NK} 1.1^{-}$and concluded that BATF negatively influences iNKT cell expansion and maturation [9]. However, recent studies have identified an important sub-population of NK1.1- iNKT cells that are fully mature and function in the periphery to regulate autoimmunity, inflammation and the host response to infection [13]. To profile NK1.1- versus NK1.1 $1^{+}$iNKT cells in Tg, WT and Batf $\rho^{\perp Z / \Delta Z}$ mice, the flow analysis was repeated to include an evaluation of NK1.1. As shown in Figure 3A, Tg mice with a reduced number of iNKT cells show a higher percentage of NK1.1 cells in all tissues. Conversely, Batf $f^{Z Z / \Delta Z}$ mice show no bias in the distribution of NK1.1 versus NK1.1 ${ }^{+}$iNKT cells in thymus and spleen, but a bias toward NK1. $1^{+}$in PLN. A graphic representation of the findings from PLN highlight the influence of BATF levels on the distribution of NK1.1 ${ }^{+}$versus NK1.1 $1^{-}$iNKT cells in the periphery (Figure 3B).

\section{Batf regulates the production of IL-17 by iNKT cells}

Peripheral NK1.1 iNKT cells respond rapidly following stimulation and produce large quantities of IL-17 [10-12]. These cells are considered a distinct lineage and are designated as iNKT-17 cells [13]. The fact that iNKT cells in CD2-HA-BATF mice are predominantly NK1.1', together with the observation that $\mathrm{Tg}$ animals display increased IL-17 expression and CD4 $4^{+}$Th17 cell numbers, suggest that BATF may regulate the differentiation of iNKT-17 cells. To examine cytokine expression by iNKT cells, splenocytes from $\mathrm{Tg}$, WT and $B a t f^{\oplus Z / \Delta Z}$ mice were stimulated in vitro with glycolipid antigen ( $\alpha$ GalCer) and ELISA were performed (Figure 4A). As expected, IL-4 is secreted efficiently by iNKT cells in WT and in Batf $f^{M / \Delta Z}$ cultures, but accumulates to a lower level in Tg cultures where there are significantly fewer iNKT cells (Figure 2 ). 
A

$$
\begin{aligned}
& -W T \\
& \text { - } T g \\
& \text { • Batfoz }
\end{aligned}
$$
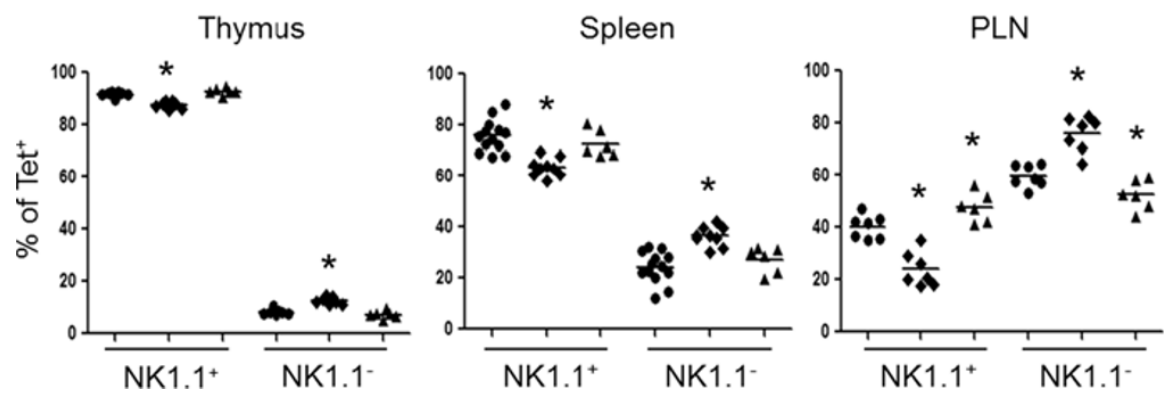

\section{B

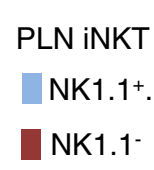

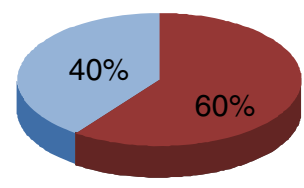

WT

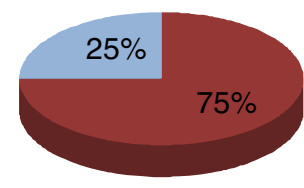

$T g$

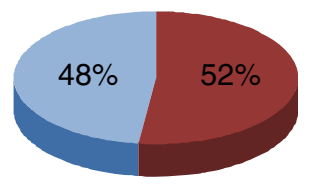

Batf $\triangle Z / \Delta Z$

Figure 3 BATF levels correlate with of NK1.1 ${ }^{-}$iNKT cells. A NK1.1 ${ }^{+}$and NK1.1 ${ }^{-}$iNKT cells were detected in cell suspensions from the indicated tissues using anti-NK1.1. Shown are the mean and distribution of the percent $\mathrm{Tet}^{+} \mathrm{NK} 1.1^{+}$versus $\mathrm{Tet}^{+} \mathrm{NK} 1.1^{-}$cells for at least 6 mice per genotype $(n \geq 6)$. ${ }^{*} p$ values $<0.05$. B Mean data from PLN in $(\mathbf{A})$ were rounded to the nearest percent and presented in pie chart format to highlight the skewing of iNKT cell populations associated with different levels of BATF expression in vivo.

For IL-17, the level of IL-17A secreted by Tg cultures was statistically indistinguishable from WT (Figure 4A), indicating that NK1.1 ${ }^{-}$cells overexpressing BATF readily produce this cytokine. On the other hand, IL-17A pro-

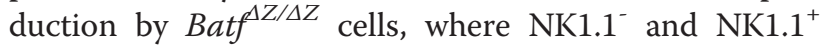
iNKT cells are present in roughly equal amounts, is dramatically less than IL-17A production by WT cells (Figure 4A). These data indicate that not only does BATF influence iNKT cell numbers, it is a critical determinant of IL-17 expression by iNKT cells. Flow cytometric analysis using intracellular staining to detect IL-17A in purified, stimulated iNKT cells from the PNL of Tg, WT and Batf ${ }^{\triangle Z / \Delta Z}$ mice provided additional evidence in support of this conclusion (Figure 4B).

\section{DN32.D3 cells model IL-17 production by iNKT cells}

IRF4/BATF protein complexes bind to DNA within the mouse $I l 17 a / f$ locus and are essential for the transactivation of the Il17a/f gene in Th17 cells [8]. However, the mechanism by which BATF functions to regulate gene expression in different cellular contexts, including iNKT-17 cells where IRF4 does not play a transcriptional role [18], continues to be investigated. Additionally, BATF and its interaction partner proteins such as JUNB and the IRF4 and 8 proteins $[8,17]$, are expressed independently of IL-17 status in other T cell lineages $[1,9]$ and BATF-containing protein complexes bind directly to genes where the transcriptional outcome is the inhibition of gene expression $[1,4,19,20]$. These facts complicate proposing a unified model to explain how BATF regulates its target genes. Therefore, to address the role of BATF in regulating $I l 17 a$ and other target genes in iNKT cells, we sought to identify an in vitro system that could be used for this purpose.

DN32.D3 cells are a murine CD4- CD8- iNKT cell hybridoma [21] that have been used to investigate the ligand specificity of the iNKT TCR [22]. In response to stimulation, DN32.D3 cells express IL-2 [23] and upregulate genes (Il4, Il10, Il13) encoding cytokines that define classic, iNKT cells (Figure 5A, top panel). Stimulation with $\alpha \mathrm{GalCer}$ also leads to the induction of several genes essential for iNKT cell development (Zbtb16 (Plzf), Nrp1, Egr1, Egr 2) [13,24] (Figure 5A, middle panel). Interestingly, stimulation with glycolipid does not change the level of endogenous Batf gene expression, but instead increases expression of the genes encoding the basic leucine zipper dimerization partners of BATF (c-Jun, JunB and JunD) (Figure 5A, bottom panel). This up-regulation of JUN family members explains the increase in AP-1 DNA binding observed previously in $\alpha$ GalCer stimulated DN32.D3 cells [9]. Stimulated DN32.D3 cells express Roryt mRNA (Figure 5A) and a very high level of Il17a mRNA (Figure 5B) which are shared features of the Th17 and iNKT-17 lineages. 


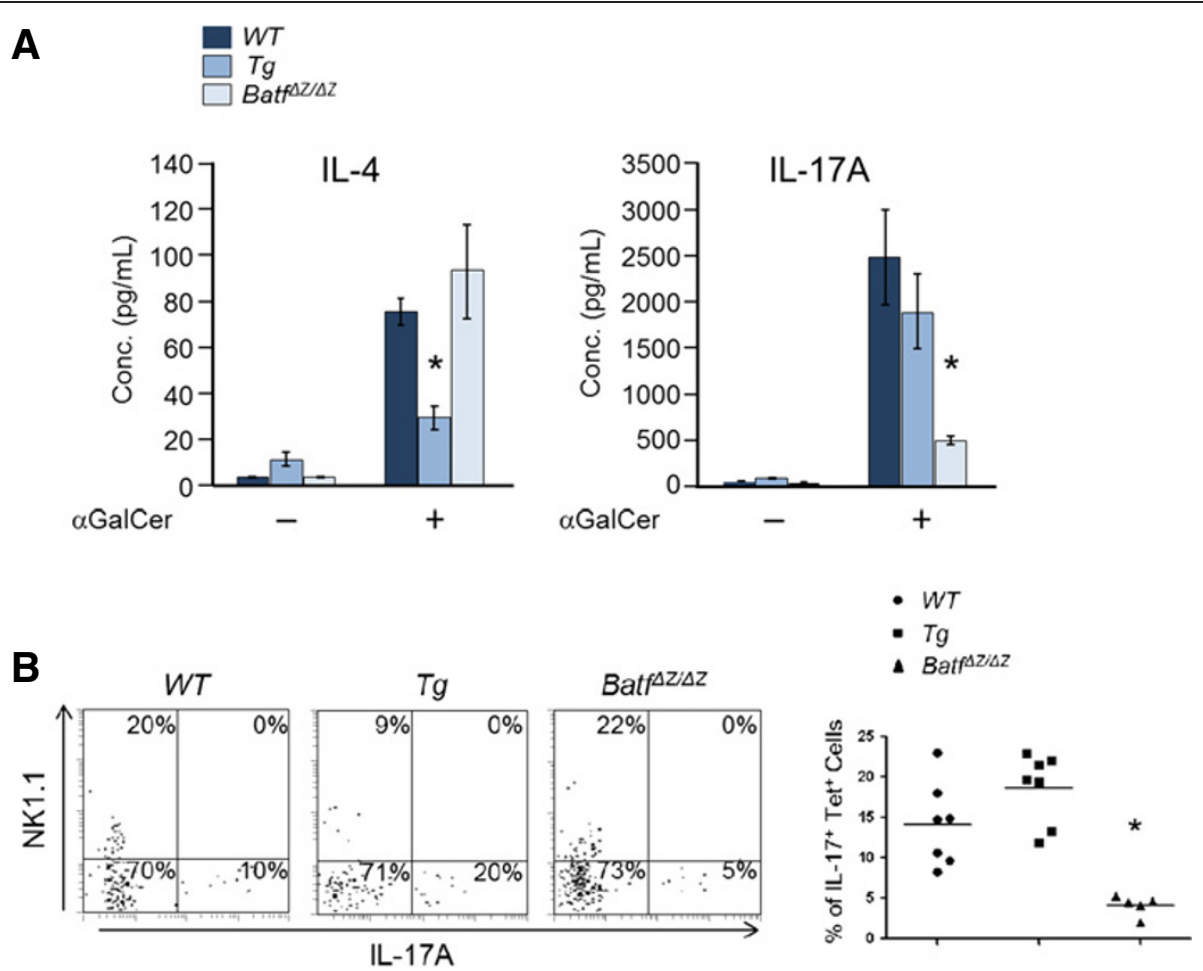

Figure 4 BATF regulates IL-17 production by primary iNKT cells. A Glycolipid-stimulated splenocytes of the indicated genotypes were analyzed by ELISA for secreted levels of IL-4 and IL-17A after $72 \mathrm{~h}$. Graphed are data averaged from 6 mice per group $(n=6)$. Bars indicate standard error. * $p$ values $<0.05$. B iNKT cells were enriched from pooled PLN of the indicated genotypes, stimulated for $4 \mathrm{~h}$, and NK1.1 ${ }^{-} I L-17 A^{+}$ cells quantified by flow cytometry. Representative plots gated on tetramer ${ }^{+}$cells are shown on the left with the $\%$ of cells in each quadrant indicated. The mean and distribution of data from at least 5 mice per genotype are presented on the right $(n \geq 5)$. ${ }^{*} p$ values $<0.05$.

However, DN32.D3 cannot be classified as true iNKT-17 cells, as they are NK1.1 $1^{+}[21]$, express Ifny mRNA when stimulated and do not express $I l 23 R$ (Figure 5A and C). Nevertheless, it is worth testing the role of BATF as a regulator of IL-17A expression in these cells.

Toward that goal, DN32.D3 cells were treated with Batf siRNA or control siRNA, stimulated with $\alpha$ GalCer loaded dimers and after $2 \mathrm{hr}$, RNA was analyzed by qRTPCR. Batf siRNA resulted in a 50\% reduction in Batf mRNA expression as well as a corresponding reduction in the level of Il17a mRNA (Figure 5C). These data support a critical role for BATF in $I l 17 a$ gene regulation while demonstrating that signaling through the iNKT cell TCR expressed by DN32.D3 cells triggers cooperating molecular events that are required for efficient IL-17 induction. We conclude that the DN32.D3 iNKT cell line is a convenient in vitro model system in which the details of these molecular events can be investigated further.

\section{Conclusions}

Our studies have identified BATF as a common regulator of lineage decisions in the murine immune system that involve the expression of IL-17. BATF joins RORyt in the transcription factor network that promotes the differentiation of IL-17 expressing cells downstream of pathways triggered by TGF $\beta$ and IL-6 in T cells [25] and by a pathway dependent on TGF $\beta$, but not IL-6, in iNKT cells $[11,26]$. These studies have characterized the DN32. D3 iNKT cell line as a model in which the regulation of Il17a gene and protein expression by this lineage can be investigated further. As the molecular details controlling IL-17 production in vivo continue to emerge, new approaches to control autoimmunity, inflammation and infectious disease will become a reality.

\section{Methods}

Mice

Batf $^{\triangle Z / \Delta Z}$ and CD2-HA-BATF mice expressing human, HA-tagged BATF were described previously [2,7] and were maintained by breeding to $\mathrm{C} 57 \mathrm{Bl} / 6$ mice (Harlan, Indianapolis, IN). Experiments were performed using sex-matched littermates between 6 and 12 wk of age. Mice were housed in a specific, pathogen-free facility. All protocols were approved by the Purdue University Animal Care and Use Committee.

\section{Antibodies and reagents}

All antibodies, cytokines and the mouse CD1d dimers were obtained from BD Biosciences unless otherwise 
A

$$
\begin{aligned}
& -\alpha \text { GalCer } \\
& +\alpha \text { GalCer }
\end{aligned}
$$
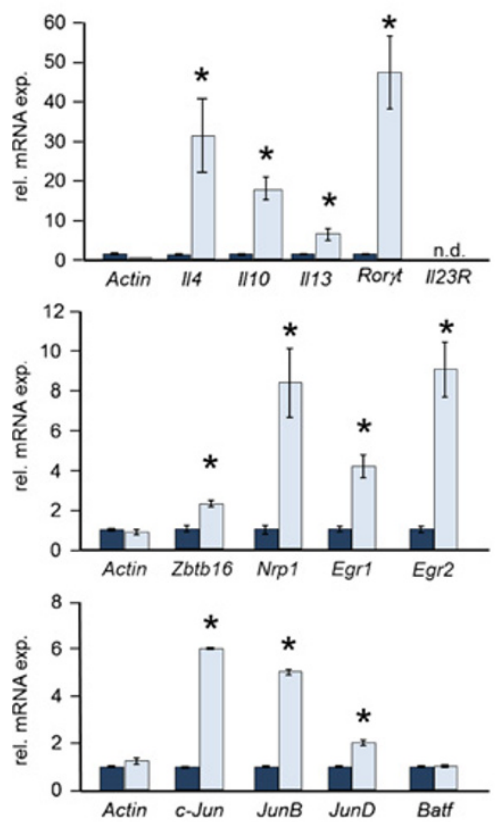

B
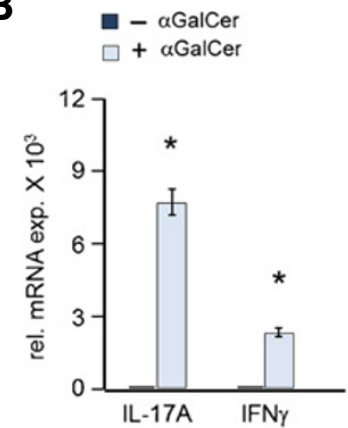

C

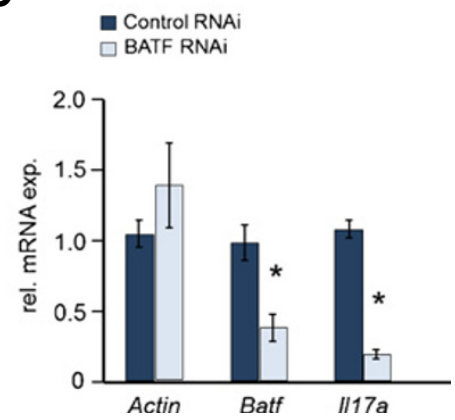

Figure 5 DN32.D3 hybridoma cells display features of iNKT-17 cells. A DN32.D3 cells were stimulated with plate-bound mouse CD1d dimers either loaded with aGalCer (+) or not (-) and after 24 h, RNA was prepared and analyzed by qRT-PCR for the indicated transcripts. Shown are the averages of 4 samples $(n=4)$. Bars indicate standard error. ${ }^{*} p$ values $<0.05$. B DN32.D3 cultures stimulated as in $(\mathbf{A})$ for $24 \mathrm{~h}$ and RNA analyzed for $1 / 17 a$ and Ifny transcripts. The mean of 4 samples is presented $(n=4)$. Bars indicate standard error. ${ }^{*} p<0.05$. C DN32.D3 cells were treated with siRNA for $24 \mathrm{~h}$, washed and stimulated as in (B) for $2 \mathrm{~h}$. RNA was isolated and analyzed for the indicated transcripts. Data shown are averaged from 5 samples $(n=5)$. Bars indicate standard error. ${ }^{*} p$ values $<0.05$.

specified. $\alpha$ GalCer was obtained from Axxora (Farmingdale, NY). PE-labeled, CD1d tetramers, empty or loaded with PBS-57, were obtained from the $\mathrm{NIH}$ tetramer core facility.

\section{Cell culture and the analysis of gene expression}

$\mathrm{CD}^{+} \mathrm{T}$ cells were isolated using MACS (Miltenyi Biotec, Auburn, CA). Cells were stimulated with antiCD3 and anti-CD28 Ab for $48 \mathrm{~h}$ as described [1]. For in vitro differentiation assays, naïve $\mathrm{CD}^{+} \mathrm{T}$ cells were isolated using MACS and cultured for $5 \mathrm{~d}$ under Th1 conditions [2] or under the following conditions for Th17: $5 \mu \mathrm{g} / \mathrm{ml}$ anti-CD3e, $2 \mu \mathrm{g} / \mathrm{ml}$ anti-CD28, $5 \mathrm{ng} / \mathrm{ml}$ rh TGF $\beta, 100 \mathrm{ng} / \mathrm{ml} \mathrm{rm} \mathrm{IL-6} \mathrm{and} 10 \mu \mathrm{g} / \mathrm{ml}$ anti-IL-4 and $10 \mu \mathrm{g} / \mathrm{ml}$ anti-IFN $\gamma$ (BioXCell, West Lebanon, NH) neutralizing antibodies. Cells were re-stimulated for $6 \mathrm{hr}$ with $2 \mu \mathrm{g} / \mathrm{ml}$ anti-CD3ع prior to analysis. DN32.D3 cells were cultured as described [9] and stimulated for $24 \mathrm{~h}$ with plate-bound CD1d dimers +/- glycolipid prior to analysis.

RNA was isolated using Trizol and analyzed by qRTPCR using SYBR green (Roche Diagnostics, Indianapolis, IN) and an ABI 7300 real-time PCR system. Data were normalized to Hprt expression and relative mRNA levels calculated using $\Delta \Delta \mathrm{Ct}$ values. The primers for Hprt, Actin, Batf, Il4, Il23R, Il17a and Il21 have been described [2]. Il10 primers were from Qiagen (Gaithersburg, MD) and additional primers (5'-3') were

Roryt: For TGTCCTGGGCTACCCTACTG, Rev GTG CAGGAGTAGGCCACATT;

Ifny: For GGATGCATTCATGAGTATTGC, Rev CC TTTTCCGCTTCCTGAGG;

cJun: For CAGTCCAGCAATGGGCACATCA, Rev GGAAGCGTGTTCTGGCTATGCA;

JunB: For GACCTGCACAAGATGAACCACG, Rev ACTGCTGAGGTTGGTGTAGACG;

JunD: For ACCTGCACAAGCAAAGCCAGCT, Rev CGAAACTGCTCAGGTTGGCGTA;

Zbtb16: For CCCAGTTCTCAAAGGAGGATG, Rev TTCCCACACAGCAGACAGAAG;

Nrp1: For GCCTGCTTTCTTCTCTTGGTTTCA, Rev GCTCTGGGCACTGGGCTACA;

Erg1: For GAGGAGATGATGCTGCTGAG, Rev TG CTGCTGCTGCTATTACC;

Erg2: For CCTCCACTCACGCCACTCTC, Rev CAC CACCTCCACTTGCTCCTG;

Il13: For GCTTATTGAGGAGCTGAGCAACA, Rev GGCCAGGTCCACACTCCATA 
For BATF knock-down, DN32.D3 cells were cultured for $24 \mathrm{~h}$ in siRNA delivery media containing $1 \mu \mathrm{M}$ BATF targeting (Accell siRNA smart pool) or non-targeting siRNA (Accell non-targeting siRNA 1) (Dharmacon/ Thermo Fisher Scientific, Waltham, MA). Cells were washed and stimulated for $2 \mathrm{~h}$ prior to analysis as described above.

\section{ELISA}

Splenocytes at a density of $5 \times 10^{6}$ cells $/ \mathrm{ml}$ were cultured with $100 \mathrm{ng} / \mathrm{ml} \alpha \mathrm{GalCer}$ for $72 \mathrm{~h}$. Supernatants were analyzed for secreted IL-4 (BD) or IL-17A (eBiosciences, San Diego, CA) using manufacturers' protocols.

\section{Flow cytometry}

Axillary, brachial, inguinal, and popliteal lymph nodes were pooled to generate PLN cultures. iNKT cells were enriched from PLN using CD8 (Ly-2) and CD19 microbeads (Miltenyi) as described [11]. Cells were surface stained after blocking with FcBlock (BD Biosciences, Franklin Lakes, NJ) using APC-anti- TCR $\beta$ (eBioscience), FITC-anti-B220, PE-Cy5-anti-B220, PBS-57-PE-CD1d tetramers and PE-Cy7-anti-NK1.1. Intracellular staining was performed as described [9] using FITC-anti-IL17A (eBioscience) after stimulation for $4 \mathrm{~h}$ with $5 \mathrm{ng} / \mathrm{ml}$ PMA and $500 \mathrm{ng} / \mathrm{ml}$ ionomycin in the presence of Golgi-plug (BD). Data were collected on a Beckman Coulter FC500 and analyzed using FCS Express V3 software (DeNovo, Los Angeles, CA).

\section{Abbreviations}

AP-1: Activator Protein-1; aGalCer: a-Galactosylceramide; PLN: Peripheral Lymph Node; qRT-PCR: quantitative Reverse Transcriptase Polymerase Chain Reaction.

\section{Competing interests}

The authors declare no conflict of interest.

\section{Authors' contributions}

$\mathrm{KLJ}-\mathrm{W}$ and EJT designed the experiments and wrote the manuscript. KLJ-W performed all experiments. KLJ-W and SP analyzed the data and prepared the figures. All authors read and approved the final manuscript.

\section{Acknowledgements}

The Flow Cytometry, DNA Sequencing and Transgenic Mouse Shared Resources of the Purdue University Center for Cancer Research played key roles in generating raw data for this study. The authors thank A. Kaufmann, J. Skiba, M. Lawson and K. Oates for routine care of mice. This work was supported by $\mathrm{NIH}$ grants CA782464 and CA114381 (EJT). Publication costs were covered by funds awarded to EJT by the Purdue University Center for Cancer Research. KLJ-W was supported by NIH T32 GM08298.

\section{Author details}

'Department of Biological Sciences and Purdue University Center for Cancer Research, Purdue University, West Lafayette, IN 47907, USA. ${ }^{2}$ Department of Biological Sciences, Hansen Life Sciences Research Building, Room 219, 201 South University Street, West Lafayette, IN, USA.

Received: 28 September 2012 Accepted: 5 March 2013 Published: 27 March 2013

\section{References}

1. Williams KL, Nanda I, Lyons GE, Kuo CT, Schmid M, Leiden JM, Kaplan MH, Taparowsky E): Characterization of murine BATF: a negative regulator of activator protein-1 activity in the thymus. Eur J Immuno/ 2001, 31(5):1620-1627.

2. Betz BC, Jordan-Williams KL, Wang C, Kang SG, Liao J, Logan MR, Kim CH, Taparowsky EJ: Batf coordinates multiple aspects of B and T cell function required for normal antibody responses. J Exp Med 2010, 207(5):933-942.

3. Ise W, Kohyama M, Schraml BU, Zhang T, Schwer B, Basu U, Alt FW, Tang J, Oltz EM, Murphy TL, et al: The transcription factor BATF controls the global regulators of class-switch recombination in both $B$ cells and $T$ cells. Nat Immunol 2011, 12(6):536-543.

4. Kuroda S, Yamazaki M, Abe M, Sakimura K, Takayanagi H, Iwai Y: Basic leucine zipper transcription factor, ATF-like (BATF) regulates epigenetically and energetically effector CD8 T-cell differentiation via Sirt1 expression. Proc Natl Acad Sci U S A 2011, 108(36):14885-14889.

5. Schraml BU, Hildner K, Ise W, Lee WL, Smith WA, Solomon B, Sahota G, Sim J, Mukasa R, Cemerski S, et al: The AP-1 transcription factor batf controls T (H)17 differentiation. Nature 2009, 460(7253):405-409.

6. Williams KL, Zullo AJ, Kaplan MH, Brutkiewicz RR, Deppmann CD, Vinson C, Taparowsky EJ: BATF transgenic mice reveal a role for activator protein-1 in NKT cell development. J Immunol 2003, 170(5):2417-2426.

7. Logan MR, Jordan-Williams KL, Poston S, Liao J, Taparowsky EJ: Overexpression of batf induces an apoptotic defect and an associated lymphoproliferative disorder in mice. Cell death \& disease 2012, 3:e310.

8. Glasmacher E, Agrawal S, Chang AB, Murphy TL, Zeng W, Vander Lugt B, Khan AA, Ciofani M, Spooner CJ, Rutz S, et al: A genomic regulatory element that directs assembly and function of immune-specific AP-1-IRF complexes. Science 2012, 338(6109):975-980.

9. Zullo AJ, Benlagha K, Bendelac A, Taparowsky EJ: Sensitivity of NK1.1-Negative NKT cells to transgenic BATF defines a role for activator protein-1 in the expansion and maturation of immature NKT cells in the thymus. $J$ Immunol 2007, 178(1):58-66.

10. Coquet JM, Chakravarti S, Kyparissoudis K, McNab FW, Pitt LA, McKenzie BS, Berzins SP, Smyth MJ, Godfrey DI: Diverse cytokine production by NKT cell subsets and identification of an IL-17-producing CD4-NK1.1- NKT cell population. Proc Natl Acad Sci U S A 2008, 105(32):11287-11292.

11. Doisne JM, Becourt C, Amniai L, Duarte N, Le Luduec JB, Eberl G, Benlagha K: Skin and peripheral lymph node invariant NKT cells are mainly retinoic acid receptor-related orphan receptor (gamma)t + and respond preferentially under inflammatory conditions. J Immuno/ 2009, 183(3):2142-2149.

12. Michel ML, Keller AC, Paget C, Fujio M, Trottein F, Savage PB, Wong CH, Schneider E, Dy M, Leite-de-Moraes MC: Identification of an IL-17 -producing NK1.1(neg) iNKT cell population involved in airway neutrophilia. J Exp Med 2007, 204(5):995-1001.

13. Godfrey DI, Stankovic S, Baxter AG: Raising the NKT cell family. Nat Immunol 2010, 11(3):197-206.

14. Pichavant M, Goya S, Meyer EH, Johnston RA, Kim HY, Matangkasombut $P$, Zhu M, Iwakura Y, Savage PB, DeKruyff RH, et al: Ozone exposure in a mouse model induces airway hyperreactivity that requires the presence of natural killer T cells and IL-17. J Exp Med 2008, 205(2):385-393.

15. Yoshiga Y, Goto D, Segawa S, Ohnishi Y, Matsumoto I, Ito S, Tsutsumi A, Taniguchi M, Sumida T: Invariant NKT cells produce IL-17 through IL-23 -dependent and -independent pathways with potential modulation of Th17 response in collagen-induced arthritis. International Journal of Molecular Medicine 2008, 22(3):369-374.

16. Simoni Y, Gautron AS, Beaudoin L, Bui LC, Michel ML, Coumoul X, Eberl G Leite-de-Moraes M, Lehuen A: NOD mice contain an elevated frequency of iNKT17 cells that exacerbate diabetes. Eur J Immunol 2011, 41(12):3574-3585.

17. Li P, Spolski R, Liao W, Wang L, Murphy TL, Murphy KM, Leonard WJ: BATFJUN is critical for IRF4-mediated transcription in T cells. Nature 2012, 490(7421):543-546.

18. Raifer H, Mahiny AJ, Bollig N, Petermann F, Hellhund A, Kellner K, Guralnik A, Reinhard K, Bothur E, Huber M, et al: Unlike alphabeta T cells, gammadelta T cells, LTi cells and NKT cells do not require IRF4 for the production of IL-17A and IL-22. Eur J Immunol 2012, 42(12):3189-3201.

19. Echlin DR, Tae HJ, Mitin N, Taparowsky EJ: B-ATF functions as a negative regulator of AP-1 mediated transcription and blocks cellular transformation by Ras and Fos. Oncogene 2000, 19(14):1752-1763.

20. Liao J, Humphrey SE, Poston S, Taparowsky EJ: Batf promotes growth arrest and terminal differentiation of mouse myeloid leukemia cells. Mol Cancer Res 2011, 9(3):350-363. 
21. Lantz O, Bendelac A: An invariant T cell receptor alpha chain is used by a unique subset of major histocompatibility complex class I-specific CD4+ and CD4-8- T cells in mice and humans. J Exp Med 1994, 180(3):1097-1106.

22. Bendelac A, Lantz O, Quimby ME, Yewdell JW, Bennink JR, Brutkiewicz RR: CD1 Recognition by mouse NK1+ T lymphocytes. Science 1995, 268(5212):863-865.

23. Brutkiewicz RR, Bennink JR, Yewdell JW, Bendelac A: TAP-independent, beta 2-microglobulin-dependent surface expression of functional mouse CD1.1. J Exp Med 1995, 182(6):1913-1919.

24. Milpied P, Massot B, Renand A, Diem S, Herbelin A, Leite-de-Moraes M, Rubio MT, Hermine O: IL-17-producing invariant NKT cells in lymphoid organs are recent thymic emigrants identified by neuropilin-1 expression. Blood 2011, 118(11):2993-3002.

25. Dong C: TH17 Cells in development: an updated view of their molecular identity and genetic programming. Nat Rev Immunol 2008, 8(5):337-348.

26. Havenar-Daughton C, Li S, Benlagha K, Marie JC: Development and function of murine RORgammat(+) iNKT cells are under TGF-beta signaling control. Blood 2012, 119(15):3486-3494.

doi:10.1186/1471-2172-14-16

Cite this article as: Jordan-Williams et al: BATF regulates the development and function of IL-17 producing iNKT cells. BMC Immunology 2013 14:16.

\section{Submit your next manuscript to BioMed Central and take full advantage of:}

- Convenient online submission

- Thorough peer review

- No space constraints or color figure charges

- Immediate publication on acceptance

- Inclusion in PubMed, CAS, Scopus and Google Scholar

- Research which is freely available for redistribution 